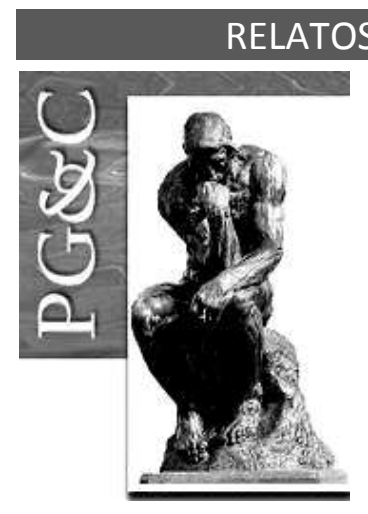

\title{
PROPOSTA DE PLANEJAMENTO PARA O SETOR LÁCTEO NO RIO GRANDE DO SUL
}

\author{
Henrique Dias Blois \\ Doutor em Engenharia da Produção pela Universidade Federal de Santa \\ Catarina, Brasil. Professor da Universidade de Passo Fundo, Brasil. \\ E-mail: blois@upf.br \\ Aliston de Oliveira Rothen \\ Graduado em Administração pela Universidade Federal de Minas Gerais, \\ Brasil. \\ E-mail: aliston.oliveira@italac.com.br \\ Maitê Peres de Carvalho \\ Doutora em Ciências da Saúde pela Universidade Federal do Rio Grande, \\ Brasil. \\ E-mail: maite carvalho@yahoo.com.br

\section{Bruno Blois Nunes} \\ Mestre em História pela Universidade Federal de Pelotas, Brasil. \\ E-mail: bruno-blois@hotmail.com
}

\section{Resumo}

Na posição de segundo maior produtor nacional de lácteos, o Rio Grande do Sul (RS) obteve aumento de produção e consequente melhoria qualitativa e produtiva nos últimos anos. A produção é dinâmica e a participação de vasto número de pequenos produtores decorre da rentabilidade do setor. Em vista da importância econômica que o setor proporciona ao estado e ao país, o presente trabalho teve como objetivo realizar um planejamento estratégico para uma empresa do setor lácteo localizada no nordeste do RS por um período de cinco anos. Dessa forma, utilizou-se o método Grumbach para a criação de cenários prospectivos. Trata-se de uma pesquisa qualitativa aplicada a peritos do setor, os quais analisaram e propuseram eventos que impactaram como pontos fortes e fracos, oportunidades e ameaças e suas inter-relações. Também foi evidenciado o grau de influência e dependência entre os eventos, o que gerou a matriz de impactos cruzados. Ademais, foram construídos e analisados possíveis cenários futuros demonstrando que a região estudada possui eventos potenciais que poderão servir como alternativas para o setor. Esses cenários contribuíram para que a empresa tomasse decisões no presente que viriam a amenizar os pontos fracos e a deixassem apta a criar estratégias para se proteger de ameaças futuras. Ademais, identificou os pontos fortes que a empresa deveria utilizar-se para aproveitar as oportunidades que provavelmente ocorreriam em um futuro próximo. Contudo, não foi identificado nenhum cenário ideal para os próximos cinco anos, fato que se deve à grande quantidade de eventos desfavoráveis.

Palavras-chave: Planejamento Estratégico. Método Grumbach. Cenários Prospectivos. Leite.

\section{PLANNING PROPOSAL \\ FOR THE DAIRY SECTOR OF RIO GRANDE DO SUL}

\begin{abstract}
In the position of second largest national dairy producer, Rio Grande do Sul (RS) obtained production increase and consequently qualitative and productive improvement in recent years. The production is dynamic and the participation of large number of small producers stems from the profitability of the
\end{abstract}

Perspectivas em Gestão \& Conhecimento, João Pessoa, v. 8, n. 1, p. 117-133, jan./abr. 2018. DOI: http://dx.doi.org/10.21714/2236-417X2018v8n1p117.

http://periodicos.ufpb.br/ojs2/index.php/pgc. ISSN: 2236-417X. Publicação sob Licença (cc)) EY-NC-ND 
industry. In view of the economic importance of the sector provides to state and the country, this study aimed to achieve a strategic planning for a company in the dairy industry located in northeast RS for a period of five years. Therefore, we used the Grumbach method for creating future scenarios. This is a qualitative research applied to industry experts, who analyzed and proposed events that impacted as strengths and weaknesses, opportunities and threats and their interrelationships. It was also evidenced the degree of influence and dependence between the events, which led to the matrix of cross impacts. Moreover, possible future scenarios were constructed and analyzed demonstrating that the study area has potential events that could serve as alternatives to the sector. These scenarios helped the company make decisions in the present that would mitigate the weaknesses and leave able to create strategies to protect against future threats. In addition, identified the strengths that the company should use to take advantage of opportunities likely occur in the near future. However, it was not identified any ideal scenario for the next five years, a fact that is due to the large amount of unfavorable events.

Keywords: Strategic Planning. Grumbach's Method. Prospective scenarios. Milk.

\section{INTRODUÇÃO}

No atual cenário econômico mundial identifica-se um período de recessão econômica devido às recentes crises financeiras que afligem o mundo. As empresas tendem a tornarem-se cada vez mais competitivas pelo fato de a oferta ser grande em relação à demanda dos processos operacionais que são exercidos pelas empresas no mercado nacional e internacional. O Brasil tem sofrido de forma incisiva tal crise e o setor lácteo tem apresentado significativas transformações na busca incessante de acompanhar as exigências do mercado (MARTINS, 2014; URDAN, A.; URDAN, F. 2006; CARVALHO, 2010).

Atualmente, o leite e seus derivados incluem-se no grupo dos alimentos mais consumidos no mundo. No Brasil, esse consumo de produtos do setor lácteo é basicamente abastecido e dominado por um aglomerado de grandes indústrias. No entanto, não se tem pleno conhecimento acerca da complexidade existente na cadeia produtiva do leite. Trata-se de um processo sui generis que tem início durante a produção primária, em cuja fase o produtor necessita da aquisição de matéria-prima proveniente de outras indústrias e passa pelo processo de produção que exige conhecimentos em áreas de ciências variadas como agrárias, sociais e humanas. 0 processo industrial também se revela complexo desde 0 princípio com a obtenção da matéria-prima e a fabricação de derivados, até a negociação e distribuição do produto (CARVALHO, 2010).

As dificuldades enfrentadas no entorno da produção do leite vêm crescendo ano a ano. Existe um conjunto de fatores que permeiam o setor trazendo apreensão aos produtores rurais, como as fraudes já descobertas na adulteração do leite, o alto custo na produção e a instabilidade dos preços no processo produtivo (ZAGONEL et al, 2016).

A instabilidade econômica em um âmbito global torna difícil a idealização do cenário nos próximos anos. O setor deve estar apto a perceber a tempo mudanças que possam ocorrer no futuro, sobretudo na área de logística e distribuição. Essa percepção visa melhorar no presente a tomada de decisões para que no futuro o setor consiga diminuir riscos e aproveitar oportunidades. É nesse contexto que os cenários prospectivos podem contribuir na formulação de estratégias visando a orientação de ações no presente que contribuam para a logística do setor lácteo, além de expor a seus gestores, ameaças e oportunidades, pontos fortes e pontos fracos, que podem ocorrer nesse setor utilizando a ferramenta de cenários como instrumentos de análise para tal problema.

O presente estudo teve como objetivo, com base na teoria de prospecção de cenários, apresentar um planejamento estratégico com previsão de cinco anos para uma empresa do setor lácteo localizada em um município à nordeste do Rio Grande do Sul.

Perspectivas em Gestão \& Conhecimento, João Pessoa, v. 8, n. 1, p. 117-133, jan./abr. 2018. 


\section{FUNDAMENTAÇÃO TEÓRICA}

\subsection{Gestão da Cadeia de Suprimentos}

A gestão da cadeia de suprimentos ou Supply Chain Management (SCM) geralmente é associada ao termo "logístico", onde vários autores trazem definições de que a cadeia de suprimentos engloba ou não o termo. Termo esse "surgido mais recentemente e que capta a essência da logística [...] e inclusive a ultrapassa" (BALLOU, 2011, p. 27).

Segundo Corrêa, o conceito chave de gestão de cadeias de suprimentos é:

[...] a administração integrada dos processos principais de negócios envolvidos com fluxos físicos, financeiros e de informações, englobando desde os produtores originais de insumos básicos até o consumidor final, no fornecimento de bens, serviços e informações, de forma a agregar valor para todos os clientes - intermediários e finais - e para outros grupos de interesse legítimos e relevantes para a cadeia [...] (CORRÊA, 2014, p. 11).

Corrêa, nessa definição, não destaca a logística ou estrutura logística como sendo um processo fora ou independente da cadeia de suprimentos, mas sim algo envolvido nos fluxos físicos da cadeia, pois "a expressão estrutura logística refere-se ao conjunto de instalações (fábricas e pontos de armazenagem) e de meios de transporte usados pela cadeia de suprimentos para o atingimento dos seus objetivos" (CORRÊA, 2014, p. 197).

Ballou (2011) nos traz a definição da cadeia de suprimentos com ênfase nos fluxos físicos dentro da cadeia, mas ele salienta que a cadeia de suprimentos é muito mais abrangente levando em consideração as interações logísticas que ocorrem entre as funções de marketing, logística e produção no âmbito empresarial.

Ainda mais prática e simples, a definição a seguir engloba todos os pontos característicos da cadeia de suprimentos das organizações levando em consideração várias observações:

A gestão da cadeia de suprimentos é um conjunto de abordagens que integra, com eficiência, fornecedores, fabricantes, depósitos e pontos comerciais, de forma que a mercadoria é produzida e distribuída nas quantidades corretas, aos pontos de entrega e nos prazos corretos, com o objetivo de minimizar os custos totais do sistema sem deixar de atender às exigências em termos de nível de serviço (SIMCHI-LEVI, D.; KAMINSKY; SIMCHI-LEVI, E. 2010, p. 33).

Tendo por base o conhecimento prévio a respeito da gestão da cadeia de suprimentos, na sequência serão abordadas as particularidades do setor lácteo, foco principal deste estudo.

\subsection{Setor Lácteo}

O aumento da produção nacional ocorreu com a significativa participação do sudeste e sul, visto que nessas regiões encontram-se os maiores produtores nacionais de leite e derivados, bem como grande parte das indústrias processadoras. A elevação da produção de lácteos quadruplicou no Rio Grande do Sul no período de 1998 a 2012; sendo que no período de 2004 a 2014 a produção de leite do estado cresceu quase o dobro da brasileira, 103,39\% contra $56,72 \%$, demonstrando a importância do setor para o país e, principalmente, para o estado (IBGE, 2014).

Perspectivas em Gestão \& Conhecimento, João Pessoa, v. 8, n. 1, p. 117-133, jan./abr. 2018. 
Na posição de segundo maior produtor nacional de lácteos, perdendo apenas para Minas Gerais, o Rio Grande do Sul obteve aumento produtivo e consequente melhoria qualitativa nos últimos anos (IBGE, 2014). De acordo com Barros, Lima e Fernandes (2010), a produção é dinâmica no estado, visto que há uma estrutura de mercado cuja produção encontra-se fragmentada entre os pequenos, médios e grandes produtores.

O setor é caracterizado pela diversidade de produtos resultando assim em inúmeros processos produtivos, mas primeiramente tem-se de definir o que é leite. Segundo o artigo 475 do decreto no 1812 de 1996, entende-se por leite "o produto oriundo da ordenha completa, ininterrupta, em condições de higiene, de vacas sadias, bem alimentadas e descansadas. O leite de outros animais deve denominar-se segundo a espécie de que proceda".

Com a definição pelas normas vigentes do país do que se trata o leite ainda precisam ser definidos os produtos oriundos da sua industrialização que são os produtos lácteos, e entende-se por produto lácteo "o produto obtido mediante qualquer elaboração do leite que pode conter aditivos alimentícios e ingredientes funcionalmente necessários para sua elaboração" (Ministério da Agricultura, Pecuária e Abastecimento [MAPA], 2005). Ainda que o leite seja derivado em vários produtos lácteos, o mesmo passa por algumas operações comuns, em todos os processos produtivos, que são mostradas na Figura 1:

Figura 1 - Etapas genéricas da indústria de produtos lácteos

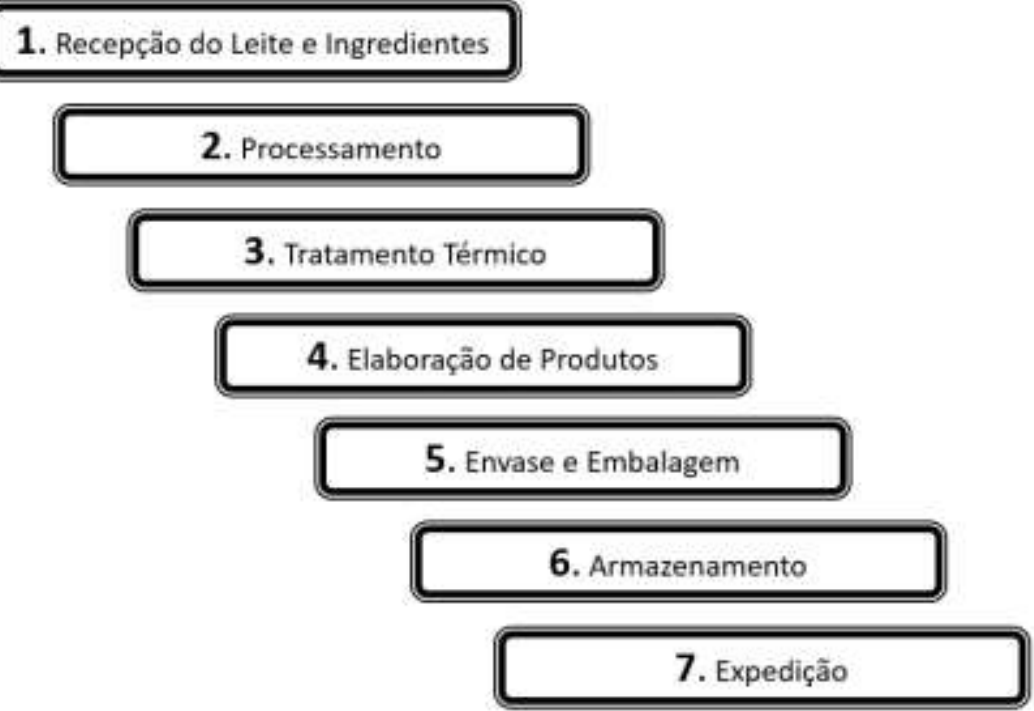

Fonte: Adaptado de Maganha (2006)

Maganha (2006) explica que no passo um o leite é transportado em caminhões isotérmicos sendo depois pesado, filtrado e encaminhado para tanques que o mantém refrigerado. Em seguida, no passo dois, o leite passa por um processamento no qual o leite in natura é filtrado (é feita a remoção de partículas grossas e impuras), clarificado (centrifugá-lo a fim de remover mais impurezas e proceder com o desnate, removendo a quantidade desejada de gordura), padronizado (no qual é feito a separação e o ajuste do teor da gordura do leite) e pasteurizado/esterilizado para consumo e/ou aquisição de seus derivados.

Já o próximo passo do processo que ocorre em todos os laticínios a fim de padronizar o leite para o produto acabado é o tratamento térmico (passo três). 
Para assegurar a destruição dos micro-organismos patogênicos, é necessário aquecer o leite a determinada temperatura, e mantê-lo nessa temperatura durante certo intervalo de tempo, antes de resfriá-lo novamente. A relação entre temperatura e tempo de retenção é importante para determinar a intensidade do tratamento térmico (MAGANHA, 2006).

No passo quatro, o leite é encaminhado para etapas produtivas posteriores para a elaboração de seus produtos e é acondicionado apropriadamente e identificado para fins de comercialização (passo cinco). No passo seis, os produtos são armazenados em condições adequadas conforme suas especificidades até serem encaminhados ao seu destino. Por fim, deve ser feita a expedição em veículos de transporte livres de qualquer presença de pragas, vazamentos, umidades, mal cheiro além de procurar evitar danos às embalagens e manter o produto na sua temperatura exigida (passo sete) (MAGANHA, 2006).

Praticamente toda a expedição no setor lácteo ocorre por meio do transporte rodoviário. Atentando-se às condições especiais de transporte como temperatura e limpeza:

Os pontos positivos do transporte rodoviário incluem alta flexibilidade para diferentes requisitos de transporte e mudanças de planos, períodos de espera menores para carga e descarga em comparação com outros modos, tempo de transporte relativamente baixo para curtas e médias distâncias, boas economias de escala sobre uma ampla faixa de distâncias de locais a internacionais (GRANT, 2013, p. 80).

Após a chegada ao supermercado, percebe-se que o consumidor tem uma necessidade e que "aumentam também as exigências [...] com vistas à disponibilização de produtos lácteos no tempo, no local, na forma e no preço que satisfaçam suas necessidades" (PADULA et al., 1999, p. 228). Desta forma, pode-se considerar o consumidor como um poderoso agente de indução de transformações ao longo de toda cadeia agroalimentar (PADULA et al, 1999, p. 228).

\subsection{Gestão de Conhecimento e Cenários Prospectivos}

Uma das formas para lidar com as constantes mudanças no ambiente organizacional é produzir, conquistar e utilizar conhecimento constantemente (SILVA, 2007). Em uma sociedade globalizada e competitiva, o conhecimento trata-se de uma importante ferramenta para o desenvolvimento (HOFFMANN, 2009).

A Gestão do Conhecimento (GC) pode ser entendida como um conjunto de procedimentos que administra a criação, propagação e utilização do conhecimento com a finalidade de alcançar os objetivos da organização (DAVENPORT; PRUSAK, 1998). É um campo bastante explorado pela administração, de caráter interdisciplinar e que abrange profissionais de áreas diversas, os quais devem articular-se habilmente para seu funcionamento (BEM; RIBEIRO JÚNIOR, 2006).

Diversos autores como Nonaka e Takeuchi (1997), Davenport e Prusak (1998) e Marcial e Grumbach (2008) identificam uma relação muito próxima entre a Gestão do Conhecimento e o estudo de Cenários Prospectivos (THIESEN, 2009). Os autores acreditam que as práticas de Gestão do Conhecimento direcionam estratégias de ação com a finalidade de preparar as organizações à tomada de decisões diante tanto das alterações ocorridas no presente como de tendências futuras (THIESEN, 2009).

Thiesen comenta que, 
a metodologia de cenários pode valer-se teoricamente das formulações produzidas no campo da Gestão do Conhecimento já que o processo de trabalho envolve todas as dimensões da espiral do conhecimento proposta por Nonaka e Takeuchi (1997), quais sejam o conhecimento compartilhado, o conceitual, o operacional e o sistêmico (2009, p. 97).

Para Porter (1989), os cenários são um dispositivo poderoso para se levar em conta a incerteza ao se fazerem escolhas estratégicas. Eles permitem que uma empresa se afaste de previsões perigosas de um único ponto de vista do futuro nos casos em que este não pode ser previsto. $\mathrm{O}$ autor define cenário, no contexto da indústria, como:

[...] uma visão internamente consistente da estrutura futura de uma indústria. É baseado em um conjunto de suposições plausíveis sobre as incertezas importantes que poderiam influenciar a estrutura industrial, considerando as implicações para a criação e a sustentação da vantagem competitiva. Um cenário industrial não é uma previsão, e sim uma estrutura futura possível (PORTER, 1989, p. 413).

A prospecção de cenários propicia ferramentas para ordenar percepções sobre ambientes futuros nos quais as decisões atuais se basearão, ou seja, são "histórias de futuro", que podem ajudar no reconhecimento dos aspectos de mudança do ambiente presente e auxiliar na adaptação a eles. O principal objetivo desse processo é estabelecer estratégias que sejam compatíveis com todos os futuros possíveis, pois, independentemente de qual futuro aconteça, deve-se estar preparado para enfrentá-lo (SCHWARTZ, 2000).

Buarque afirma que embora não possam ser eliminadas as incertezas, nem definidas categoricamente as trajetórias futuras da realidade estudada, as metodologias de construção de cenários contribuem para delimitar as possíveis evoluções da realidade. Assim, pode-se afirmar que a construção de cenários permite contribuir, em determinada realidade integrada numa rede de relações internas e externas ao contexto empresarial, de forma a indicar, com certa segurança, objetivos e rumos para as ações (BUARQUE, 2003).

Nos últimos anos, vem-se valorizando cada vez mais a construção de cenários em face à necessidade do planejamento, tanto em sua dimensão decisória quanto operativa, dispondo de subsídios informativos que facilitem prever os acontecimentos e reduzir impactos negativos num processo devidamente fundamentado em perspectiva proativa. Atualmente existem vários métodos na literatura que auxiliam na construção de cenários prospectivos. Mas, independentemente da técnica utilizada, a análise de múltiplos cenários é uma ferramenta eficiente para examinar incertezas e expandir o pensamento das pessoas. Marcial e Grumbach (2008) salientam que, para construir cenários e definir estratégias, é necessário usar ferramentas simples, a fim de que os resultados possam ser assimilados pelos usuários.

Com a definição dos processos envolvendo o leite in natura como suas exigências sanitárias e governamentais fica visível que não estamos trabalhando com qualquer insumo de um processo operacional, muito pelo contrário, pois um insumo primário sofre uma série de procedimentos e podem ramificar-se em uma quantidade imensa de produtos acabados como queijos, manteiga, leite em pó, leite UHT e outros.

Com a descrição da gestão de cadeias de suprimentos, fica clara a necessidade de um planejamento das operações e fluxos, envolvendo desde o leite insumo até o leite produto acabado inserido na cadeia. No entanto, é imprescindível o planejamento na expedição do produto acabado dos laticínios a longo prazo. Apesar da cadeia de suprimentos ser muito ampla, a literatura abordada deu certo enfoque à logística inserida na cadeia de suprimentos com a finalidade de expedição de produtos acabados. 


\section{PROCEDIMENTOS METODOLÓGICOS}

O presente trabalho utiliza a metodologia de cenários prospectivos, através do método descrito por Grumbach (2005), para responder a seguinte questão: quais são as ações que devem ser tomadas hoje na distribuição de produtos lácteos de uma empresa desse setor, visando aproveitar as oportunidades e pontos fortes para os próximos 5 anos (2016-2020). Para tanto, este estudo de caso trabalhou com oito peritos em uma unidade de uma empresa do setor lácteo localizada na região nordeste do estado do Rio Grande do Sul.

O método Grumbach (2005) baseia-se na perspectiva de que existem vários futuros possíveis e de que o futuro não será, necessariamente, uma extrapolação do passado. Para atingir o objetivo final dos estudos de cenários prospectivos, ou seja, a definição das estratégias da organização, Grumbach propõe, primeiramente, que seja identificado o objeto de estudo. Tal processo é iniciado com o conhecimento ou a definição do problema pelo pesquisador. Definem-se de forma clara os contornos e limites desse problema, bem como seus elementos essenciais: amplitude geográfica, nível de profundidade e horizonte temporal; também são definidos quais serão os peritos convidados a participar do trabalho. Na sequência, verifica-se o diagnóstico estratégico, que consiste na pesquisa do problema, quando será realizado minucioso levantamento das variáveis externas e internas do sistema em pauta, a saber: pesquisa retrospectiva, construção de uma imagem do estado atual e entendimento das causas e origens da situação atual. Esta fase é finalizada com a elaboração de um documento contendo o diagnóstico de cada tema inicialmente proposto.

Logo após, o processamento consiste na construção ou identificação das várias alternativas de futuro. Para tanto, está prevista a descrição da pesquisa realizada pelos analistas e a identificação dos elementos que possam conter os fatos portadores de futuro (variáveis endógenas e exógenas ao objeto de estudo). Segundo Chiavenato (2003) forças exógenas são "forças externas que provem do ambiente", já as forças endógenas "são as forças internas que criam necessidade de mudança estrutural e comportamental". Com base nos fatos portadores de futuro, identificam-se as rupturas de tendências, tendo como resultado a concepção de eventos futuros. Marcial e Grumbach fazem algumas sugestões a serem utilizadas durante a depuração da lista de eventos gerados, como a de que os peritos se posicionem no final do horizonte temporal estabelecido e procurem deixar sua imaginação livre o suficiente para produzir eventos com real possibilidade de ocorrência e que tenham importância para a organização (MARCIAL; GRUMBACH, 2008).

Pelo disposto por Marcial e Grumbach (2008), para construir cenários e elaborar estratégias é preciso utilizar ferramentas simples de assimilação. Nas técnicas de criatividade, o método brainstorming é uma forma de trabalho em grupo onde a intenção maior é produzir o máximo de soluções possíveis para um problema previamente identificado.

Para as técnicas de avaliação, o sistema conta com a ferramenta Delphi, a qual consiste em criar um questionário que é utilizado para a obtenção de respostas dos peritos, as quais vão sendo utilizadas na obtenção de consensos e na formulação de novas perguntas. Ao final do questionário, o método disponibiliza uma média ponderada das respostas apresentadas nos questionários aplicados sobre a probabilidade do evento disposto no instrumento. Considerando que o estudo aborda um grupo de especialistas ligados ao setor lácteo, a técnica Delphi adaptou-se de forma coesa na metodologia de avaliação da pesquisa, visto que busca extrair e maximizar todas aquelas vantagens que apresentam os métodos baseados em grupos de experts, além de minimizar seus inconvenientes gerados. Ademais, aproveita a sinergia do debate em grupo e elimina as interações sociais indesejáveis existentes dentro de todo o grupo, buscando assim, a

Perspectivas em Gestão \& Conhecimento, João Pessoa, v. 8, n. 1, p. 117-133, jan./abr. 2018. 
elaboração de uma espécie de acordo ou consenso o mais consistente e legítimo possível, de forma que possa ser confiável (CAMARGO, 2005).

A técnica Delphi torna-se uma das ferramentas mais eficazes de análise quantitativa pelo fato de que consiste em interrogar individualmente os peritos, pelo fato de se tratar de uma metodologia que busca a convergência de opiniões e tentar minimizar os problemas típicos, como a pressão social para concordar com os demais, certa influência pela personalidade dominante sobre a opinião dos demais do grupo e influências de interesse particular de um único indivíduo ou do grupo (MARCIAL; GRUMBACH, 2008).

De forma complementar ao sistema Delphi, este estudo utiliza-se da ferramenta de impactos cruzados. Marcial e Grumbach (2008) afirmam que o método de impactos cruzados consiste em um composto de métodos que visa avaliar qual impacto teria um determinado evento diante da possibilidade de ocorrência de um outro evento, considerando-se a interdependência entre esses eventos.

Para tratar os impactos como probabilidades condicionais, é necessário que os impactos e as probabilidades informados pelos peritos sejam submetidos ao "Teorema de Bayes" (MARCIAL; GRUMBACH, 2008).

Todas as probabilidades e influências apontados pelos peritos devem estar de acordo com o Teorema de Bayes, o qual considera o grau de conhecimento dos peritos, evitando assim possíveis inconsistências, princípios das probabilidades subjetivas (BUSSAB; MORETTIN, 2013). Caso as probabilidades apresentem inconsistência, o software Puma pode não ser capaz de efetuar os cálculos. Sendo assim, devem-se corrigir as inconsistências ocasionadas pelas divergências das respostas.

Imaginem-se dois eventos (A) e (B) aos quais são associadas as seguintes probabilidades:

$P(A)=$ probabilidade de $A$ ocorrer;

$P(B)=$ probabilidade de $B$ ocorrer;

$P(A / B)=$ probabilidade de $A$ ocorrer, desde que $B$ tenha ocorrido;

$\mathrm{P}(\mathrm{B} / \mathrm{A})=$ probabilidade de $\mathrm{B}$ ocorrer, desde que $\mathrm{A}$ tenha ocorrido.

O teorema também pode ser explicado pela seguinte expressão:

$$
\operatorname{Pr}(A \mid B)=\frac{\operatorname{Pr}(B \mid A) \operatorname{Pr}(A)}{\operatorname{Pr}(B)}
$$

Na etapa seguinte, por meio da motricidade e da dependência, é possível verificar quais eventos exerciam maior influência sobre os demais através da motricidade. Os eventos dependentes, por sua vez, são aqueles que sofrem influência dos demais (MARCIAL; GRUMBACH, 2008).

Através do método Grumbach, foram analisados e interpretados os dez primeiros cenários que se constituem em ocorrência ou não ocorrência dos eventos, os mesmos são classificados em três tipos, o "mais provável", o de "tendência" e ainda o "ideal" e, por meio deles, foram elaboradas ações estratégicas propostas pelos peritos.

\section{ANÁLISE E DISCUSSÃO DOS RESULTADOS}

Este estudo de caso buscou identificar ações por meio de cenários prospectivos a fim de elaborar um planejamento estratégico para uma empresa do setor lácteo localizada em um município à nordeste do Rio Grande do Sul até 2020, podendo assim antecipar-se de ameaças que venham a atingi-la, a fim de que a empresa esteja preparada para o futuro.

Perspectivas em Gestão \& Conhecimento, João Pessoa, v. 8, n. 1, p. 117-133, jan./abr. 2018. 
Inicialmente foram colhidas informações sobre o setor em estudo no que tange a distribuição de produtos lácteos no país e no MERCOSUL (Mercado Comum do Sul), com a finalidade de elaborar eventos que seriam apresentados aos peritos selecionados. Peritos esses que, segundo Marcial e Grumbach (2008), devem ser especialistas no assunto e detentores de uma visão macro e micro do ambiente em que a organização está inserida. Para tanto, definiram-se os oito peritos participantes da pesquisa, os quais foram escolhidos devido à sua experiência e conhecimento intrínsecos ao setor lácteo.

Na sequência, realizou-se um levantamento das forças endógenas e exógenas que pudessem interferir na cadeia de distribuição. Essa fase foi finalizada com a criação de um relatório, utilizando-se o levantamento das forças endógenas e exógenas a fim de elaborar os 18 eventos preliminares, os quais utilizaram-se da técnica de brainstorming, cuja intenção é produzir o máximo de soluções possíveis para um determinado problema (Quadro 1).

Quadro 1 - Eventos preliminares com potencial de impacto no setor lácteo

\begin{tabular}{|c|c|}
\hline Código & Descrição dos eventos \\
\hline $\mathbf{0 1}$ & Aumento da concorrência entre transportadores na unidade estudada \\
\hline $\mathbf{0 2}$ & Aumento de expedição de produtos acabados da unidade estudada \\
\hline $\mathbf{0 3}$ & Aumento no faturamento da unidade estudada \\
\hline $\mathbf{0 4}$ & Aumento na exigência de controles dos produtos acabados pelos clientes \\
\hline $\mathbf{0 5}$ & Piora nos processos internos necessários para o bom funcionamento da expedição \\
\hline $\mathbf{0 6}$ & Aumento de veículos contratados para atender a demanda da unidade estudada \\
\hline $\mathbf{0 7}$ & Diminuição da mão de obra na distribuição da unidade estudada \\
\hline $\mathbf{0 8}$ & Aumento de carteira de transportadores cadastrados na unidade estudada \\
\hline $\mathbf{0 9}$ & Piora nos meios de acondicionamento dos produtos acabados na unidade estudada \\
\hline $\mathbf{1 0}$ & Aumento de controles internos para um bom acondicionamento do produto \\
\hline $\mathbf{1 1}$ & Piora nos modais de transportes para atender especificações de carregamento \\
\hline $\mathbf{1 2}$ & Aumento do tempo usado para o carregamento na unidade estudada \\
\hline $\mathbf{1 3}$ & Melhora na capacitação de todos os colaboradores envolvidos na expedição \\
\hline $\mathbf{1 4}$ & Melhora no acesso de informações entre as unidades na expedição \\
\hline $\mathbf{1 5}$ & Aumento e produtos, volumes a serem distribuídos \\
\hline $\mathbf{1 6}$ & Aumento de controles do estoque de produtos acabados na unidade estudada \\
\hline $\mathbf{1 7}$ & Melhora nos controles de qualidade dos produtos para evitar recalls \\
\hline $\mathbf{1 8}$ & Piora nos processos de expedição conforme a necessidade e capacidade do cliente \\
\hline
\end{tabular}

Fonte: Dados da pesquisa

Após, aplicou-se a técnica Delphi, em duas rodadas, visando selecionar os dez eventos definitivos, os quais se encontram distribuídos no quadro 2 "em ordem decrescente dos valores médios das pertinências atribuídas pelos peritos" (GRUMBACH, 2005). Para tanto, utilizou-se os seguintes parâmetros: a) eventos que apresentassem probabilidade $\geq 60 \%$ (muito provável de ocorrerem nos próximos cinco anos) e b) pertinência $\geq 7$ (bem alta em relação ao objeto de estudo), conforme a opinião dos peritos.

Quadro 2 - Eventos definitivos

\begin{tabular}{|c|c|}
\hline Código & Descrição dos eventos definitivos \\
\hline $\mathbf{0 2}$ & Aumento de expedição de produtos acabados da unidade estudada \\
\hline $\mathbf{0 3}$ & Aumento no faturamento da unidade estudada \\
\hline $\mathbf{1 5}$ & Aumento e produtos, volumes a serem distribuídos \\
\hline $\mathbf{1 0}$ & Aumento de controles internos para um bom acondicionamento do produto \\
\hline $\mathbf{0 6}$ & Aumento de veículos contratados para atender a demanda da unidade estudada \\
\hline $\mathbf{1 6}$ & Aumento de controles do estoque de produtos acabados na unidade estudada \\
\hline $\mathbf{1 3}$ & Melhora na capacitação de todos os colaboradores envolvidos na expedição \\
\hline
\end{tabular}

Perspectivas em Gestão \& Conhecimento, João Pessoa, v. 8, n. 1, p. 117-133, jan./abr. 2018. 


\begin{tabular}{|c|c|}
\hline $\mathbf{1 4}$ & Melhora no acesso de informações entre as unidades na expedição \\
\hline $\mathbf{1 7}$ & Melhora nos controles de qualidade dos produtos para evitar recalls \\
\hline $\mathbf{0 1}$ & Aumento da concorrência entre transportadores na unidade estudada \\
\hline
\end{tabular}

Fonte: Dados da pesquisa

Após serem definidos os dez eventos definitivos, foi realizada a última consulta aos peritos, conhecida como matriz de impactos cruzados. Essa matriz consiste em avaliar a influência que a ocorrência de determinado evento teria sobre os demais, bem como a dependência que esses eventos possuem entre si (MARCIAL; GRUMBACH, 2008). O Quadro 3 serve de orientação aos peritos sobre como preencher suas respectivas matrizes de impactos cruzados.

Quadro 3 - Impactos Cruzados - Orientações aos Peritos

\begin{tabular}{|c|c|}
\hline Impactos & Peso \\
\hline É certo que ocorre & +5 \\
\hline Aumenta fortemente a probabilidade & +4 \\
\hline Aumenta consideravelmente a probabilidade & +3 \\
\hline Aumenta moderadamente a probabilidade & +2 \\
\hline Aumenta fracamente a probabilidade & +1 \\
\hline Não altera a probabilidade & 0 \\
\hline Diminui fracamente a probabilidade & -1 \\
\hline Diminui moderadamente a probabilidade & -2 \\
\hline Diminui consideravelmente a probabilidade & -3 \\
\hline Diminui fortemente a probabilidade & -4 \\
\hline É certo que não ocorre & -5 \\
\hline
\end{tabular}

Fonte: Software Puma 4.0

Nesta etapa, todas as probabilidades e influências apontadas pelos peritos devem estar de acordo o Teorema de Bayes. Na etapa seguinte, foi possível verificar quais eram os eventos que exerciam maior influência sobre os demais através da motricidade. Na Figura 1, é demonstrado o plano de motricidade e dependência dos eventos observados na empresa estudada.

Figura 1 - Motricidade e Dependência

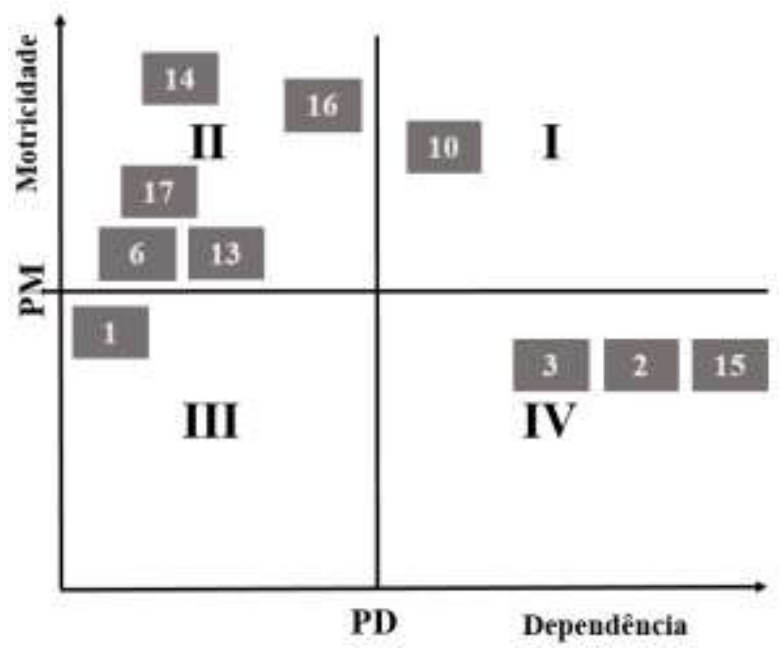

Fonte: Dados da pesquisa 
Conforme Marcial e Grumbach (2008), as variáveis explicativas são aquelas localizadas no quadrante I, apresentando grande motricidade e pouca dependência, representando as variáveis que condicionam o restante do sistema, neste caso, somente o evento 10 . Já as variáveis de ligação, localizadas no quadrante II, são muito motrizes e possuem grande dependência das demais, como os eventos $6,17,14,13$ e 16 . O evento 1 , localizado no quadrante III, representa os eventos autônomos que, por sua vez, possuem pouca relação com o sistema. Pelo método Grumbach os eventos do quadrante III podem ser excluídos da análise pelo fato de serem pouco influentes e poucos dependentes. Por fim, as variáveis de resultado, localizadas no quadrante IV, são aquelas muito dependentes e pouco influentes. As ações desses eventos pouco impactam os demais, mas as ações dos outros impactam fortemente os eventos deste quadrante que são o 3, 2 e 15.

\subsection{Geração de Cenários}

Depois de definida a matriz de impactos cruzados e corrigidas as possíveis inconsistências, o software de apoio Puma 4.0 gera os cenários prospectivos que, por sua vez, gera um mapa com os cenários de maior probabilidade. Os cenários são constituídos de combinações de ocorrências e não ocorrências de eventos.

Nesta etapa, o software formulará os cenários. Segundo os princípios de análise combinatória, para cada evento (n) se terá $2^{n}$ cenários diferentes. Para Grumbach, o ideal é trabalhar com dez eventos, sendo assim, serão gerados 1.024 cenários possíveis. Esse método especifica ainda que, devido à complexidade de analisar 1.024 cenários, devem-se analisar os dez de maior probabilidade de ocorrência. No setor de expedição da empresa estudada, os dez cenários de maior probabilidade de ocorrência estão explicitados no Quadro 4.

Quadro 4 - Dez cenários de maior probabilidade de ocorrência.

\begin{tabular}{|c|c|c|c|c|c|c|c|c|c|c|c|}
\hline Cenários & Prob(\%) & E.1 & E.2 & E.3 & E.6 & E.10 & E.13 & E.14 & E.15 & E.16 & E.17 \\
\hline C.1 & 64,236 & $\mathrm{O}$ & $\mathrm{O}$ & $\mathrm{O}$ & $\mathrm{O}$ & $\mathrm{O}$ & $\mathrm{O}$ & $\mathrm{O}$ & $\mathrm{O}$ & $\mathrm{O}$ & $\mathrm{O}$ \\
\hline C.2 & 15,920 & $\mathrm{~N}$ & $\mathrm{O}$ & $\mathrm{O}$ & $\mathrm{O}$ & $\mathrm{O}$ & $\mathrm{O}$ & $\mathrm{O}$ & $\mathrm{O}$ & $\mathrm{O}$ & $\mathrm{O}$ \\
\hline C.3 & 4,865 & $\mathrm{O}$ & $\mathrm{O}$ & $\mathrm{O}$ & $\mathrm{O}$ & $\mathrm{O}$ & $\mathrm{O}$ & $\mathrm{O}$ & $\mathrm{O}$ & $\mathrm{O}$ & $\mathrm{N}$ \\
\hline C.4 & 3,927 & $\mathrm{O}$ & $\mathrm{O}$ & $\mathrm{O}$ & $\mathrm{O}$ & $\mathrm{O}$ & $\mathrm{N}$ & $\mathrm{O}$ & $\mathrm{O}$ & $\mathrm{O}$ & $\mathrm{O}$ \\
\hline C.5 & 3,286 & $\mathrm{O}$ & $\mathrm{O}$ & $\mathrm{O}$ & $\mathrm{O}$ & $\mathrm{O}$ & $\mathrm{O}$ & $\mathrm{N}$ & $\mathrm{O}$ & $\mathrm{O}$ & $\mathrm{O}$ \\
\hline C.6 & 1,104 & $\mathrm{~N}$ & $\mathrm{O}$ & $\mathrm{O}$ & $\mathrm{O}$ & $\mathrm{O}$ & $\mathrm{O}$ & $\mathrm{O}$ & $\mathrm{O}$ & $\mathrm{O}$ & $\mathrm{N}$ \\
\hline C.7 & 0,954 & $\mathrm{O}$ & $\mathrm{O}$ & $\mathrm{O}$ & $\mathrm{N}$ & $\mathrm{O}$ & $\mathrm{O}$ & $\mathrm{O}$ & $\mathrm{O}$ & $\mathrm{O}$ & $\mathrm{O}$ \\
\hline C.8 & 0,896 & $\mathrm{~N}$ & $\mathrm{O}$ & $\mathrm{O}$ & $\mathrm{O}$ & $\mathrm{O}$ & $\mathrm{N}$ & $\mathrm{O}$ & $\mathrm{O}$ & $\mathrm{O}$ & $\mathrm{O}$ \\
\hline C.9 & 0,753 & $\mathrm{O}$ & $\mathrm{O}$ & $\mathrm{O}$ & $\mathrm{O}$ & $\mathrm{O}$ & $\mathrm{O}$ & $\mathrm{O}$ & $\mathrm{O}$ & $\mathrm{N}$ & $\mathrm{O}$ \\
\hline C.10 & 0,750 & $\mathrm{~N}$ & $\mathrm{O}$ & $\mathrm{O}$ & $\mathrm{O}$ & $\mathrm{O}$ & $\mathrm{O}$ & $\mathrm{N}$ & $\mathrm{O}$ & $\mathrm{O}$ & $\mathrm{O}$ \\
\hline
\end{tabular}

Fonte: Dados da pesquisa

Legenda: C-Cenários. E-Eventos. O-Ocorre. N-Não ocorre

Nota-se no quadro 4 que apenas os dez primeiros cenários representam $96,661 \%$ das probabilidades de ocorrência; e os cenários restantes, representam 3,309\% de probabilidades. Esse quadro denomina em cada cenário a ocorrência ou não de dado evento, aliado à probabilidade de ocorrência. Nesse contexto, percebe-se que no cenário 1 , mais provável, com $64,236 \%$ de probabilidade de ocorrência, todos os eventos ocorrem.

\subsubsection{O Cenário mais Provável}

O cenário mais provável é aquele que o software Puma coloca no topo da relação de cenários possíveis. Para Marcial e Grumbach (2008), o cenário mais provável é aquele que, 
segundo os peritos, tem a maior probabilidade de ocorrência no horizonte temporal considerado, no caso deste trabalho, o período de cinco anos. Os autores explicitam que não é uma previsão, mas o futuro mais provável em um conjunto de vários futuros possíveis. Os analistas devem realizar a correlação lógica dos eventos sempre com base nas pesquisas feitas anteriormente, para então criar o caminho que leva ao final do horizonte temporal estabelecido. Após realizado o encadeamento lógico dos acontecimentos, o analista deve procurar no cenário alguns acontecimentos:

- Acontecimentos desfavoráveis fora do objeto de estudo - Caracterizam-se pela ocorrência de eventos desfavoráveis e a não ocorrência de eventos favoráveis ao objeto de estudo, não podendo alterar a probabilidade de ocorrência dos eventos. Aqui se devem propor ações para melhor proteger-se desses eventos desfavoráveis. Neste estudo não foram identificados acontecimentos desfavoráveis fora do objeto de estudo.

- Acontecimentos desfavoráveis dentro do objeto de estudo - Caracterizam-se como a ocorrência dos eventos desfavoráveis ao objeto de estudo e a não ocorrência dos eventos favoráveis. Nesses eventos, as ações realizadas no presente podem alterar as probabilidades de ocorrência no futuro.

Evento 2 - Aumento de expedição de produtos acabados da unidade estudada: Com o aumento da expedição, a unidade acaba apenas sendo informada do que deve carregar. Isso ocorre algumas vezes quando a unidade está com certo problema operacional e não demonstra capacidade de atender ao aumento da expedição. A ação necessária é que ocorra troca de informações entre as unidades de forma clara e objetiva, proporcionando à unidade estudada se programar e identificar possíveis desvios operacionais.

Evento 3 - Aumento no faturamento da unidade estudada: Como o faturamento não ocorre nesta unidade e a pessoa encarregada dessa parte administrativa também tem de auxiliar a outra unidade da empresa, acaba ocasionando sobrecarga ao setor de faturamento. Dessa forma, ocorre a chegada de caminhões a fim de atender esse aumento de faturamento, porém não são identificadas a carga, seu destino e tampouco a necessidade da emissão de documentos para acompanhar tal carga. Também ocorre o fato de alguns caminhões passarem tempo superior a 24 horas aguardando na fila para o carregamento, o que gera um maior custo à empresa tendo de arcar com diárias extras. Uma medida importante a ser considerada seria destinar alguém exclusivo para atender a demanda dessa unidade, ou ainda, sendo a medida mais ideal, essa parte ser feita na própria unidade, não dependendo de nenhum outro setor ou mesmo da outra unidade da empresa.

Evento 4 - Aumento de veículos contratados a fim de atender a demanda da unidade estudada: Como a procura por veículos é alta para atender a demanda dessa unidade, o setor responsável pela admissão acaba contratando todo o tipo de veículo. Atualmente, a unidade carrega caminhões bi trens com tampa baixa e tampa alta, carretas sider, baú e container. Mas nem sempre o veículo contratado é ideal para o produto e quantidade estipulada. Carretas com capacidade para 24 pallets PBR (padrão brasileiro, 1,00 $\mathrm{m} \times 1,20 \mathrm{~m}$ ) seria ideal serem tampa baixa, sider ou baú, mas ocorre de serem carregados 24 pallets em carretas tampa alta, graneleiras, sendo necessário o dobro de tempo e de mão de obra para baixar e levantar as tampas para o carregamento. A medida a ser tomada é o setor responsável verificar junto à transportadora o tipo de veículo e tentar encaixar as quantidades aos veículos mais apropriados para o volume e produto a ser expedido.

Evento 15 - Aumento de produtos e volumes a serem distribuídos: Com esses aumentos, alguns produtos necessitam ser palletizados novamente a fim de usufruir melhor a capacidade dos veículos. Porém, a informação acaba chegando de uma maneira não muito clara a respeito do modo de ser palletizada ou da possibilidade de ser palletizada novamente. Mais uma vez ocorre uma falha importante na troca de informações entre as unidades acerca do melhor modo de carregar certos produtos ou ainda a disponibilidade de mão de obra para

Perspectivas em Gestão \& Conhecimento, João Pessoa, v. 8, n. 1, p. 117-133, jan./abr. 2018. 
palletizar essas cargas conforme o solicitado. A medida a ser tomada é aumentar a troca de informações, principalmente no que concerne à uma unidade informar suas intenções de como expedir os produtos e ver se a outra unidade é capaz de atender tais especificações.

- Acontecimentos favoráveis dentro do objeto de estudo - Caracterizam-se pela ocorrência de eventos favoráveis e pela não ocorrência de eventos desfavoráveis ao objeto de estudo. Nesse caso, devem-se articular ações no presente para que o objeto de estudo saiba tirar melhor proveito dos acontecimentos futuros que lhes são favoráveis.

Evento 10 - Aumento de controles internos para um bom acondicionamento do produto: Apesar da unidade estudada trabalhar apenas com produtos de estoque seco, os mesmos têm de ser armazenados corretamente, seguindo o prazo de validade e a organização por lotes. Para que isso seja feito de maneira eficiente deve ser aumentado o controle de rastreabilidade do leite desde a recepção até o local armazenado, passando por todos os elos da cadeia produtiva da empresa.

Evento 12 - Melhora na capacitação de todos os colaboradores envolvidos na expedição: Como a demanda vem aumentando na expedição, a unidade estudada está tendo de buscar por novos colaboradores para integrarem a empresa. O que acontece é que nem todos esses colaboradores contratados estão capacitados a exercerem integralmente as funções necessárias para que não ocorram erros de informações. A empresa está tendo de contratar e treinar funcionários para cargos de suma importância para o bom funcionamento da expedição, como conferentes de carregamento e operadores de empilhadeiras. A maneira de ir melhorando essa questão é focar prioritariamente nessa capacitação dos novos colaboradores por meio de treinamento e supervisão da operação a fim de corrigir futuros desvios e, consequentemente, prejuízos.

Evento 14 - Melhora no acesso de informações entre as unidades na expedição: Com a melhora nessa troca de informações, a unidade estudada pode se programar para atender a demanda e até mesmo corrigir atrasos na expedição. Com a informação em mãos a respeito de qual carga e como ela será carregada, a unidade pode antecipar ou realocar colaboradores para determinadas funções necessárias, como remontar pallets ou deixar certa quantidade de carga em posição de ser carregada imediatamente, contudo, isso depende da unidade estar em poder das informações, as quais podem ser fornecidas por e-mail ou telefone.

Evento 16 - Aumento de controles do estoque de produtos acabados na unidade estudada: Conforme explicitado anteriormente, os produtos não exigem especificações muito elevadas de armazenamento por tratar-se de produtos de estoque seco. No entanto, deve-se aumentar o controle das datas de fabricação seguindo o FIFO (Fbirst In First Out) e de produtos com possíveis desvios de qualidade, sendo esses identificados e segregados para o não carregamento até uma resolução do que será feito com tal produto. Esse aumento de controle depende do setor que monitora o estoque de produtos acabados e da colaboração do setor de PCP (Planejamento e Controle de Produção) juntamente com o controle de qualidade para identificar e segregar esses produtos. Já o controle de FIFO deve ser realizado verificando fisicamente no estoque datas mais antigas e destinando-as para o carregamento.

Evento 17 - Melhora nos controles de qualidade dos produtos para evitar recalls: Como a matéria prima da empresa é o leite e ele é altamente volátil no seu processamento, ocorrem muitas vezes desvios de padrão de qualidade, algumas vezes identificados apenas quando o produto está acabado e já se encontra em estoque. Tanto que para evitar que tais produtos entrem no mercado, é adotado o sistema de quarentena para todos os produtos da unidade, apenas variando o tempo dessa quarentena para cada produto, a qual tem como principal função identificar desvios em tempo hábil a fim de evitar a expedição desses produtos. Isso pode ser feito com a interação, novamente, do PCP, controle de qualidade e controle de estoque da unidade para identificar datas, horários e lotes que ocorreram desvios, para a definição final se o produto está apto ou não para expedição aos consumidores.

Perspectivas em Gestão \& Conhecimento, João Pessoa, v. 8, n. 1, p. 117-133, jan./abr. 2018. 
- Acontecimentos favoráveis fora do objeto de estudo - Caracterizam-se pela ocorrência de eventos favoráveis e pela não ocorrência de eventos desfavoráveis ao objeto de estudo. Nesse caso esses eventos são forças exógenas em que a empresa não pode tomar medidas para mudar tais cenários, mas os mesmos são positivos para a empresa.

Evento 1 - Aumento da concorrência entre transportadores na unidade estudada: Com o aumento de produção e consequentemente aumento de expedição de produtos da unidade, irá aumentar a concorrência entre as transportadoras para serem contratadas a fim de expedir tais cargas. A empresa pode se beneficiar da lei da oferta e da procura, cuja a oferta é maior que a procura, ocasionando queda de preços pelo serviço das transportadoras e fazendo com que o custo da expedição diminua.

\subsubsection{O Cenário de Tendência}

Marcial e Grumbach (2008) salientam que o cenário de tendência é aquele que provavelmente ocorrerá caso o curso dos acontecimentos se mantenha conforme o momento presente. Cenário esse que leva em consideração a possibilidade de ocorrerem rupturas, ou seja, o surgimento de fatos que importam ao objeto de estudo e, em consequência, possam interferir nos eventos futuros. Neste estudo não foi identificada nenhuma ruptura, por isso, não se estabeleceu nenhum cenário de tendência.

\subsubsection{O Cenário Ideal}

Para Marcial e Grumbach (2008), cenário ideal é aquele em que ocorrem os eventos favoráveis e não ocorrem os desfavoráveis. Neste estudo não foi identificado nenhum cenário ideal em que ocorresse apenas eventos favoráveis para os próximos cinco anos.

Tendo em vista os eventos favoráveis e desfavoráveis encontrados neste estudo, pode observar-se que a construção de cenários, observando tendências e potencialidades, além de complexo também depende de variáveis de difícil previsão, todavia são fundamentais para o planejamento do setor lácteo no Brasil. Ademais, observa-se que uma apropriada organização das etapas de um processo empresarial é indispensável para o bom andamento do serviço e consequente lucro.

Outrossim, um setor tão heterogêneo não pode estabelecer metas fixas, pois sempre deve haver flexibilidade e adaptação com o decorrer dos avanços e desafios enfrentados. Seja no campo científico, empresarial ou mesmo político, ainda há muitos passos a galgar desde o incremento da produção até a produtividade e competitividade do setor lácteo diante do mercado nacional e internacional. É importante ter em mente que pesquisas com cenários prospectivos dependem de inúmeras variáveis como mercado, políticas públicas, investimentos em pesquisa e adoção de tecnologias que refletem na lucratividade em diferentes níveis do setor. Sendo assim, destaca-se a relevância de políticas públicas que valorizem o setor como um todo a fim de que o país supere seus pontos fracos e aprimore suas qualidades para que ocupe um cenário muito além das atuais projeções.

\section{CONSIDERAÇÕES FINAIS}

Buscou-se, com esse estudo, identificar se a construção de cenários prospectivos para a unidade estudada seria de real proveito para a empresa do setor lácteo em pauta. Esses cenários contribuíram para que a empresa tomasse decisões que virão a amenizar os pontos fracos da mesma e deixá-la apta a criar estratégias para proteger-se de ameaças futuras. 0 estudo também identificou os pontos fortes que a empresa deve-se utilizar para aproveitar as oportunidades que provavelmente ocorrerão em um futuro próximo.

Perspectivas em Gestão \& Conhecimento, João Pessoa, v. 8, n. 1, p. 117-133, jan./abr. 2018. 
Para que isso ocorra, a empresa deve tomar medidas imediatas para a diminuição, principalmente, dos pontos fracos, onde a principal falha ocorre na troca de informações pela falta de independência de seus processos logísticos, ficando claro que a empresa apenas expede a produção sem poder interferir em nenhum fluxo externo da logística, faturamento e contratação. $O$ adequado seria fazer um diagnóstico aprofundado no setor e identificar as falhas específicas que vem ocorrendo, bem como as formas de expedição que foram tomadas de maneira acertada a curto prazo. Já a longo prazo a empresa deveria ter uma unidade de logística completa, com contratação, faturamento, logística reversa e recall, fato que diminuiria o tempo perdido na troca de informações e seria de responsabilidade interna melhorar falhas que possam surgir futuramente.

Nesse contexto, visualiza-se que a metodologia proposta por Grumbach realmente auxilia na realização de um planejamento estratégico para empresas pelo fato de apontar quais devem ser as prioridades a fim de se protegerem melhorando seus processos internos e, consequentemente, sua lucratividade.

Ademais, ressalta-se a importância de futuros estudos que abordem outros aspectos e detalhem de forma diferenciada o processo de trabalho explorando os achados sob outra perspectiva. Dessa forma será possível estabelecer maior consistência na prospeç̧ão dos cenários e ampliar a visão de futuro visando um planejamento completo e adequado às necessidades particulares desse setor.

\section{REFERÊNCIAS}

BALLOU, Ronald H. Gerenciamento da cadeia de suprimentos/logística empresarial. 5. ed. Porto Alegre: Bookman, 2011.

BARROS, Fabiano Luiz Alves; LIMA, João Ricardo Ferreira de; FERNANDES, Rosangela Aparecida Soares. Análise da estrutura de mercado na cadeia produtiva do leite no período de 1998 a 2008. Revista de Economia e Agronegócio, v.8, n.2, p. 177-198, 2010.

BEM, Roberta Moraes de; RIBEIRO JÚNIOR, Divino Ignácio. A Gestão do Conhecimento dentro das organizações: a participação do bibliotecário. Revista ACB, v.11, n.1, p. 75-82, jan./jul. 2006.

BRASIL. Instituto Brasileiro de Geografia e Estatística [IBGE]. Produção da Pecuária Municipal. v.42, 2014.2 Disponível em: http://biblioteca.ibge.gov.br/visualizacao/periodicos/84/ppm 2014 v42 br.pdf. Acesso em: 16 jan. 2017.

BRASIL. Ministério da Agricultura, Pecuária e Abastecimento. Instrução Normativa no 16, de 23 de agosto de 2005. Aprova o Regulamento Técnico de Identidade e Qualidade de Bebida Láctea. Diário Oficial da União, Poder Executivo, Brasília, DF, 24 de ago. 2005. Seção 1, p. 7. Disponivel em: http://www.normasbrasil.com.br/norma/instrucao-normativa-162005 75591.html Acesso em: 16 jan. 2017.

BRASIL. Decreto no 1812, de 8 de fevereiro de 1996. Altera dispositivos do Decreto $n^{\circ} 30.691$, de 29 de março de 1952, que aprovou o Regulamento da Inspeção Industrial e Sanitária de Produtos de Origem Animal, alterado pelo Decreto ${ }^{\circ} 1.255$, de 25 de junho de 1962. Diário Oficial da União, Poder Executivo, Brasília, DF, 9 de fev. 1996. Seção 1, p. 2241. Disponível em: 
https://www.planalto.gov.br/ccivil 03/decreto/1996/D1812.htm\#art1. Acesso em: 16 jan. 2017.

BUARQUE, Sérgio. Metodologia e técnicas de construção de cenários globais e regionais. Instituto de Pesquisa Econômica Aplicada (IPEA), Texto para discussão no 939, 2003.

BUSSAB, Wilton de Oliveira; MORETTIN, Pedro Alberto. Estatística Básica. 8. ed. São Paulo: Saraiva, 2013.

CAMARGO, Odair. Uma contribuição metodológica para planejamento estratégico de corredores de transporte de carga usando cenários prospectivos. 2005. Tese (Doutorado em Engenharia de Produção) - Universidade Federal de Santa Catarina (UFSC), Florianópolis, 2005.

CARVALHO, Glauco Rodrigues. A Indústria de laticínios no Brasil: passado, presente e futuro. Circular Técnica. Embrapa Gado de Leite. Juiz de Fora, MG, 2010.

CHIAVENATO, Idalberto. Introdução à Teoria Geral da Administração. 7. ed. Rio de Janeiro: Elsevier, 2003.

CORRÊA, Henrique Luiz. Administração de cadeias de suprimentos e logística: o essencial. São Paulo: Atlas, 2014.

DAVENPORT, Thomas H.; PRUSAK, Laurence. Conhecimento empresarial. Rio de Janeiro: Elsevier, 1998.

GRANT, David. Gestão de logística e cadeia de suprimentos. São Paulo: Saraiva, 2013.

GRUMBACH, Raul José dos Santos. Método Grumbach de Planejamento Estratégico e Cenários Prospectivos. Guia. Rio de Janeiro, 2005.

HOFFMANN, W. A. M. Gestão do conhecimento: desafios de aprender. São Carlos: Compacta, 2009.

MAGANHA, Martha Faria Bérnils. Guia técnico ambiental da indústria de produtos lácteos. São Paulo: CETESB, 2006.

MARCIAL, Elaine Coutinho; GRUMBACH, Raul José Santos. Cenários Prospectivos: como construir um futuro melhor. 5. ed., Rio de Janeiro: FGV, 2008.

MARTINS, Paulo do Carmo; OLIVEIRA, Angela de Fátima. O melhor ano em trinta. Revista Leite \& Derivados, v.146, p.10-12, 2014.

PADULA, Antônio; CASTRO, Cléber; FENSTERSEIFER, Jaime; MATTUELLA, Juvir; MÜLLER, Laudemir. A cadeia de suprimento no setor agroindustrial leiteiro no Rio Grande do Sul: uma análise das estratégias empresariais frente ao Mercosul. Indicadores Econômicos FEE, v.26, n. 4, p.218-231, 1999.

PORTER, Michael. Vantagem competitiva: criando e sustentando um desempenho superior. Rio de Janeiro: Campus, 1989.

Perspectivas em Gestão \& Conhecimento, João Pessoa, v. 8, n. 1, p. 117-133, jan./abr. 2018. 
Programa PUMA 4.0. Disponível em: http://www.brainstorming.com.br. Acesso em: 12 dez. 2016.

SCHWARTZ, Peter. A arte da visão de longo prazo: planejando o futuro em um mundo de incertezas. São Paulo: Best Seller, 2000.

SILVA, Heide Miranda. Gestão do conhecimento e inteligência competitiva em organizações: uma abordagem conceitual. Revista de Iniciação Científica da FFC, v.7, n.1, p.84-93, 2007.

SIMCHI-LEVI, David; KAMINSKY, Philip; SMICHI-LEVI, Edith. Cadeia de suprimentos projeto e gestão: conceitos, estratégias e estudos de caso. 3. ed. Porto Alegre: Bookman, 2010.

THIESEN, Juares da Silva. Método para a construção e análise de cenários prospectivos em planejamento educacional baseado na gestão do conhecimento. 2009. Tese (Doutorado em Engenharia e Gestão do Conhecimento) - Universidade Federal de Santa Catarina, Florianópolis, 2009.

URDAN, Flávio Torres; URDAN, André Torres. Gestão do composto de marketing. São Paulo: Atlas, 2006.

ZAGONEL, Tiago Reginaldo; TRENNPOHL, Dilson; AMARAL, Volmir Ribeiro; BRUMANN, Licurgo Lauda; BAGGIO, Daniel Knebel. A cadeia produtiva do leite: discussões sobre a crise do setor lácteo na região celeiro do Estado do Rio Grande do Sul. Revista da Universidade Vale do Rio Verde, v. 14, n. 2, p. 191-205, 2016.

Artigo recebido em 19/01/2017 e aceito para publicação em 24/03/2018 